\title{
Long versus short cephalomedullary nail for trochanteric femur fractures (OTA 31-A1, A2 and A3): a systematic review
}

\author{
John Dunn ${ }^{1}$ Nicholas Kusnezov ${ }^{1} \cdot$ Julia Bader $^{1}$ - Brian R. Waterman ${ }^{1}$. \\ Justin Orr $^{1} \cdot$ Philip J. Belmont ${ }^{1}$
}

Received: 1 August 2015/Accepted: 4 April 2016/Published online: 19 April 2016

(c) The Author(s) 2016. This article is published with open access at Springerlink.com

\begin{abstract}
Background Both long and short cephalomedullary nails $(\mathrm{CMN})$ may be used to treat trochanteric femur fractures. The objective of this paper was to compare the clinical outcomes between long and short $\mathrm{CMN}$ in the treatment of trochanteric hip fractures.

Materials and methods A literature search was performed, identifying 135 papers; 4 of which met inclusion and exclusion criteria. Papers included were those that compared cohorts of long and short nails for stable trochanteric femur fractures of level III evidence or superior. Data was pooled and analyzed, focusing on reoperation rate, secondary femoral shaft fracture rate, estimated blood loss, transfusion rate, operative time and length of stay.

Results Included in the analysis were 1276 patients, with 438 short and 838 long CMN. The average age was 82.0 years for short CMN and 79.0 years for long CMN $(P=0.0002)$. The average follow up was 18 months, $46 \%$ were male, and $71 \%$ had an ASA (American Society of Anesthesiologists score) classification $\geq 3$. The rate of reoperation was $5.0 \%$ and $3.8 \%$ for short and long CMN, respectively $(P=0.31)$. The rate of refracture was $1.6 \%$ and $0.95 \%$ for short and long CMN, respectively $(P=0.41)$. As compared to long nails, short nails had an average blood loss of $39 \mathrm{~mL}$ less $(P=0.0003)$, an $8.8 \%$ decrease in transfusion rate $(P=0.07)$, and incurred 19 min less operative time $(P<0.0001)$. No significant
\end{abstract}

John Dunn

dunnjohnc@gmail.com

1 Department of Orthopaedic Surgery and Rehabilitation, William Beaumont Army Medical Center, 5005 North Piedras St., El Paso, TX 79920-5001, USA differences between short and long nails were observed for either other complications, hardware complications, nonunion, or mortality.

Conclusions For trochanteric femur fractures, short CMN have a low reoperation rate while significantly decreasing operative time and estimated blood loss with the additional benefit of being cost effective.

Level of evidence Level 3.

Keywords Hip fracture - Hospital cost .

Cephalomedullary nail $\cdot$ Reoperation

\section{Introduction}

The frequency of hip fractures is increasing steadily with an aging and increasingly physical active population $[1,2]$. It is estimated that by 2050 , there will be 6.26 million hip fractures world-wide annually. By the age of 80 years, $20 \%$ of women will have sustained a hip fracture, and by 90 years, nearly $50 \%$ of women will have had a hip fracture [3]. Furthermore, the 1-year mortality for hip fractures is roughly $20 \%[4,5]$.

Stable trochanteric femur fractures are most often fixed by cephalomedullary nails (CMN) or sliding hip screws (SHS). For stable fracture patterns, CMN has been shown to be equivalent to SHS in terms of stability [6]. However, the SHS construct has been found to provide inadequate fixation in more unstable fractures types [7, 8], more often leading to malreduction [9] and lag screw cut-out [10]. CMN have been increasingly favored as a more reliable option for hip fracture fixation, and the utilization of CMN is increasing [11], especially among younger surgeons [12].

Both short and long CMN are available options for hip fracture fixation. Short nails offer the advantages of shorter 
operative times, reduced blood loss, and lower transfusion rates [13, 14]. Conversely, long nails offer the theoretical benefit of protecting the full length of the femur, particularly in elderly patients with osteoporotic or osteopenic bone, thus potentially decreasing secondary femoral shaft refracture rates [15]. However, because of the limited power of the individual retrospective comparative studies, differences in rates of secondary femoral shaft refracture reoperation have not been found to be significant $[13,14$, $16,17]$.

We hypothesize that by pooling data from all available comparative cohorts regarding CMN fixation of extracapsular AO type $31 \mathrm{~A}$ fractures, there will be no difference in reoperation and secondary femoral shaft refracture rates of short and long CMN. Furthermore, by conducting a number needed to treat to harm and concomitant cost analysis comparing the combined reoperation and secondary femoral shaft refracture rates of the short and long $\mathrm{CMN}$ derived from our systematic review, we hypothesize that short CMN are significantly more cost effective.

\section{Materials and methods}

The present study is reported following PRISMA guidelines [18]. There was no source of funding or support for this analysis.

\section{Eligibility}

The inclusion criteria for the present analysis comprised papers that (1) reviewed results of treatment of patients with simple or multifragmentary intertrochanteric femur fractures (31-A1, A2, and A3); (2) compared results from patients treated with long $\mathrm{CMN}$ versus short $\mathrm{CMN}$ fixation; (3) followed patients for a minimum of 1 year; and (4) included description and rate of reoperation and periprosthetic fracture. Only studies written in the English language were considered.

Studies were excluded if they (1) did not include both short and long CMN cohorts; or (2) had less than 1 year follow up. One paper [16] included fractures other than the $31 \mathrm{~A}$ type. In this analysis, all non-31A fractures (113 fractures from the study by Vaughn et al. [16]) and the respective data were excluded from the present analysis.

\section{Outcomes}

The primary outcome measures were the rates of (1) reoperation, (2) periprosthetic fracture, and (3) mortality. We additionally isolated reoperation due to nonseptic failure as well as reoperation due to mechanical failures alone. Nonseptic failures excluded infection as a cause for revision. Mechanical failures included failures of the implant, such as screw cut-out, loosening, fixation failure, and prominent screws, excluding revision for pain without implant failure. The secondary outcome measures were (1) blood loss, (2) number of RBC units transfused, (3) number of patients transfused, (4) operative time, (5) length of hospital stay, (6) nonunion, and (7) complications. We isolated complications other than periprosthetic fracture as well as hardware complications specifically. Demographic data were also collected and pooled.

\section{Search strategy and selection of studies}

A systematic search was performed for all articles published on the treatment of intertrochanteric femur fractures with cephalomedullary fixation using the PubMed, Medline, EMBASE, and Cochrane databases between the years 1990 and 2015. Search terms included, cephallomedullary*, intertroch*, trochanteric fracture nail*, extracapsular fracture*, short*, and long*.

The abstracts generated by the search were individually assessed for relevance by two senior authors (B.R.W. and P.J.B.). Full manuscripts of individual studies were then thoroughly reviewed independently according to the inclusion and exclusion criteria. If the data was not explicitly stated in the manuscript, the corresponding author was contacted for further information. Any disagreements or discrepancies in study selection were moderated by consensus.

\section{Assessment of methodological quality and data collection}

The GRADE (Grading of Recommendations Assessment, Development and Evaluation Working Group) criteria are a quality assessment template used to evaluate the quality of methods in study analysis [19]. Using this template, the quality of the selected studies was independently assessed by the two senior authors (B.R.W. and P.J.B.). Disagreement concerning study quality was moderated by consensus. For all previously identified studies deemed eligible, the authors extracted pertinent data.

\section{Data pooling across studies and data analysis}

Demographic data, primary outcome measures, and secondary outcome measures from comparable studies were pooled for all patients, those receiving a short CMN, and those receiving a long CMN. None of the studies received external funding and no clear sources of bias were identified. Outcome measures were compiled and compared. 


\section{Statistical analysis}

Continuous variables were compared with use of the Student $t$ test, and categorical data were compared with use of either the Fisher exact test or the Chi square test. A $P$ value of $<0.05$ was considered significant. Analyses were performed using SAS version 9.3 (SAS Institute, Cary, NC).

A number needed to harm analysis was conducted given the absolute risk reduction in both refracture and reoperation between the short and long CMN cohorts. Furthermore, we performed a post hoc power analysis given the existing data to determine the sample size necessary to produce statistical significance between the short and long CMN cohorts with respect to both refracture and reoperation.

\section{Results}

The search resulted in 135 potentially eligible studies, while only 4 met inclusion and exclusion criteria (Fig. 1). All studies were retrospective comparative cohorts, level III therapeutic studies [13, 14, 16, 17] (Table 1). In total, 1179 patients, with 438 short and 838 long CMN, were included. Patients were treated with one of the following four CMN: Gamma 3 short (Stryker, Kalamazoo, MI), gamma 2 and 3 long nails (Stryker), or Synthes Trocanteric Fixation Nail short or long nail (Synthes, Paoli, PA). The average age was 82.0 years and 79.0 years, for short and long nails, respectively $(P=0.0002)$. The average followup was 18 months, $46 \%$ were male, and $71 \%$ had an ASA
(American Society of Anesthesiologists score) classification $\geq 3$ (Table 1).

\section{Outcome measure reporting}

Intraoperative variables and hospital length of stay were recorded (Table 2). Two studies reported estimated blood loss, transfusion rates, and length of stay [13, 14]. The average blood loss was 86.7 and $135.2 \mathrm{~mL}$ for short and long CMN, respectively $(P=0.0003)$. The blood transfusion rate was $41 \%$ for short and $50 \%$ for long CMN $(P=0.07)$. The length of hospital stay was 7.0 and 7.3 days for short and long CMN, respectively $(P=0.48)$. Three studies reported operative time $[13,14,17]$. The mean operative time was $47.1 \mathrm{~min}$ for short $\mathrm{CMN}$ and 65.6 min for long CMN $(P<0.0001)$.

All studies recorded reoperation, refracture, and other complications (Table 3). The overall rate of reoperation was 5.0 and $3.8 \%$ for short and long CMN, respectively $(P=0.31)$. The rate of reoperation due to non-septic failure was $4.8 \%$ for short and $3.3 \%$ for long CMN $(P=0.20)$ while that due to secondary to mechanical failure was $3.7 \%$ and $2.5 \%$ for short and long CMN, respectively $(P=0.25)$.

The rate of refracture was $1.60 \%$ for short $\mathrm{CMN}$ and $0.95 \%$ for long CMN $(P=0.31)$. The rate of other complications was $4.6 \%$ and $5.25 \%$ for short and long CMN, respectively $(P=0.57)$. There was no statistically significant difference between short and long CMN for other complications, hardware complications, non-union, or mortality.
Fig. 1 Cohort inclusion and exclusion

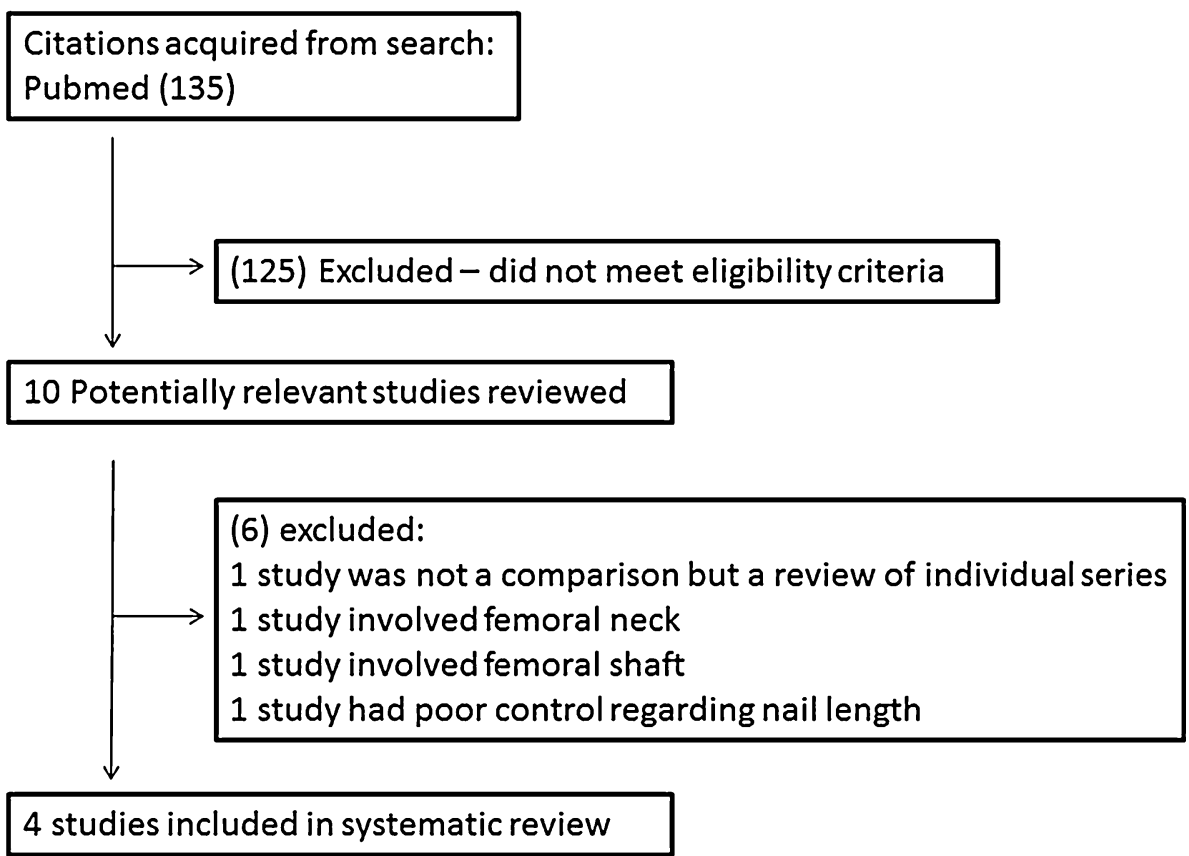


Table 1 Demographics. ASA American Society of Anesthesiologists score,NR not reported

\begin{tabular}{|c|c|c|c|c|c|c|}
\hline Author & Fractures & $\begin{array}{l}\text { Follow-up } \\
\text { (months) }\end{array}$ & Male & Age (years) & $\mathrm{ASA} \geq 3$ & $\begin{array}{l}\text { OTA classification } \\
\text { (31A1/A2/A3) }\end{array}$ \\
\hline \multirow[t]{3}{*}{ Hou et al. [14] } & 283 & 37 & 73 & 79 & 171 & $126 / 157 / 0$ \\
\hline & 100 short & & & 81 & & $59 / 41 / 0$ \\
\hline & 183 long & & & 78.6 & & $67 / 116 / 0$ \\
\hline \multirow[t]{3}{*}{ Boone et al. [13] } & 194 & 12 & 54 & 81.1 & NR & $59 / 142 / 0$ \\
\hline & 82 short & & & 83.3 & & $31 / 51 / 0$ \\
\hline & 119 long & & & 79.6 & & $28 / 91 / 0$ \\
\hline \multirow[t]{3}{*}{ Vaughn et al. [16] } & 143 & 12 & NR & NR & NR & $36 / 79 / 28$ \\
\hline & 37 short & & & & & $11 / 19 / 7$ \\
\hline & 106 long & & & & & $25 / 60 / 21$ \\
\hline \multirow[t]{3}{*}{ Kleweno et al. [17] } & 559 & 12 & 349 & 84 & 426 & $\mathrm{NR}^{\mathrm{a}} / \mathrm{NR}^{\mathrm{a}} / 143$ \\
\hline & 219 short & & & & & NR \\
\hline & 430 long & & & & & NR \\
\hline
\end{tabular}

${ }^{\mathrm{a}}$ Reported 416 31A1/A2 fractures, combined

Table 2 Intraoperative variables and hospital length of stay

\begin{tabular}{lccr}
\hline & Short nail & Long nail & $P$ value \\
\hline Age, mean (SD) & $82.0(8.1)$ & $79.0(9.1)$ & 0.0002 \\
EBL (mL), mean (SD) & $96.7(67.2)$ & $135.2(139.7)$ & 0.0003 \\
RBC (units) & & & 0.8166 \\
$1-2$ & $37(37.0 \%)$ & $68(37.2 \%)$ & \\
$3-5$ & $4(4.0 \%)$ & $10(5.5 \%)$ & \\
$>5$ & $1(1.0 \%)$ & $5(2.7 \%)$ & 0.0738 \\
Patients transfused & $75(41.2 \%)$ & $151(50.0 \%)$ & $<0.0001$ \\
Operative time (min), mean (SD) & $47.1(18.4)$ & $65.6(32.5)$ & 0.4737 \\
Length of stay (days), mean (SD) & $7.0(4.5)$ & $7.3(4.1)$ & \\
\hline
\end{tabular}

Table 3 Refracture, reoperation, and complication rates

\begin{tabular}{lrrr}
\hline & \multicolumn{1}{c}{ Short nail } & Long nail & $P$ value \\
\hline Reoperation & $22(5.02 \%)$ & $32(3.82 \%)$ & 0.3103 \\
Reoperation due to aseptic failure & $21(4.79 \%)$ & $28(3.34 \%)$ & 0.1996 \\
Reoperation due to mechanical failure & $16(3.65 \%)$ & $21(2.51 \%)$ & 0.2463 \\
Refracture & $7(1.60 \%)$ & $8(0.95 \%)$ & 0.3112 \\
Other complications & $20(4.57 \%)$ & $44(5.25 \%)$ & 0.5949 \\
Hardware complications & $14(3.20 \%)$ & $32(3.82 \%)$ & 0.5713 \\
Nonunion & $1(0.23 \%)$ & $5(0.60 \%)$ & 0.3611 \\
Mortality & $22(5.02 \%)$ & $42(5.01 \%)$ & 0.9932 \\
\hline
\end{tabular}

Although the refracture and reoperation were not statistically significant between the two groups, a number needed to harm was calculated as a worst case scenario. The calculated number needed to treat to harm for refracture and all-cause reoperation for short over long CMN were calculated to be 154 and 83 , respectively.

The studies did not report mortality uniformly. Vaughn et al. [16]. did not report mortality. In the study by Kleweno et al. [17], the authors found that 175 of 698 patients died prior to 12-month follow up. These patients were excluded from any further analysis. Similarly, Boone et al. [13]. did not distinguish between short and long CMN patient mortality but noted that 41 of 194 patients died within 1year. Conversely, Hou et al. [14]. reported 9/58 short and 15/68 long CMN deaths within 1 year. While the mortality rate between long and short CMN could not be compared in this analysis, the pooled 1-year mortality rate was $26.5 \%$. 


\section{Discussion}

In this systematic review, there was a small but statistically insignificant increase in all-cause reoperation and secondary femoral shaft refracture with short versus long $\mathrm{CMN}$ in the setting of stable trochanteric femur fractures. The current study only includes the most third generation of the short CMN, including the Stryker Gamma 3 short and Synthes Trochanteric Fixation Nail short, which have been reported to have decreased rates of post-operative secondary femoral shaft fractures [15]. An argument could be made that the average $38.5 \mathrm{~mL}$ increase in estimated blood loss and $18.5 \mathrm{~min}$ increase in operative time with implantation of a long versus short CMN is not clinically significant. However, the surgeon must consider the increased cost associated with use of the long CMN.

The higher cost of the long CMN is most heavily influenced by the increased operative time (Table 4). The difference in operative time between the short and long $\mathrm{CMN}$ is most likely attributed to additional time spent reaming the canal for the long $\mathrm{CMN}$, and the method of the distal interlock screw insertion. The cost of running the operating room depends on many factors, including type and complexity of surgical procedure, fixed versus variable overhead costs, and the professional fees of the surgeon and anesthesia provider [20]. It is estimated that operating rooms cost, on average, US $\$ 62 \mathrm{~min}^{-1}$; ranging from as low as US \$22 to as high as US $\$ 133 \mathrm{~min}^{-1}$ [20]. The true cost to the hospital is unpublished as institutions do not typically openly disclose profit margins. These figures do not account for implant costs and provider fees.
Provider fees vary based on means of compensation from fixed salary to hourly wages. In a review of two anesthesia departments in academic institutions, the hourly staffing cost was found to range from US $\$ 111$ to $\$ 176$ with a median of $\$ 122$ [21]. Though the pay per minute for orthopaedic surgeons in the operating room is unpublished, the median hourly pay of an orthopaedic surgeon in the United States is \$204-210 [22, 23]. Therefore, provider fees would foreseeably cost another $(\$ 122+\$ 204) /$ $60 \min =\$ 5$ per minute to the hospital. Combined with the cost of running the operating room for an additional $18.5 \mathrm{~min}$, the long CMN would cost an additional $(\$ 62+\$ 5) \times 18.5 \mathrm{~min}=\$ 1248$. These estimates are still conservative as they do not include costs for other personnel including operating room and recovery nursing, surgical technicians, other medical staff who may be required to treat the effects of longer surgeries with more blood loss, and the associated costs of increased blood transfusions.

Finally, with regard to the differences in implant pricing, at our institution the average long CMN costs roughly $\$ 2400$ while the short CMN costs $\$ 1800$ (Depuy Synthes; https://www.depuysynthes.com/). The cost of a long nail is further increased by the additional locking screw (\$230) and reaming rod (\$130). Altogether, considering the basic pricing differences, locking screw, and reaming rod, a long CMN costs approximately $\$ 960$ more than a short nail. Combining the aforementioned factors again yields a conservative cost estimate of $(\$ 1248+\$ 960)=\$ 2208$ more for utilization of a long $\mathrm{CMN}$ compared to a short CMN.

Table 4 Long cephalomedullary nails (CMN) cost analysis (US \$)

\begin{tabular}{|c|c|c|c|}
\hline Contributing factors & Cost & Calculation & Additional cost for long $\mathrm{CMN}$ \\
\hline Operative time & $\$ 62 / \mathrm{min}$ & $\$ 62 / \min \times(65.6-47.1 \mathrm{~min})$ & $\$ 1147$ \\
\hline \multicolumn{4}{|l|}{ Provider fees } \\
\hline Orthopaedic surgeon & $\$ 207 / \mathrm{h}$ & $(\$ 329 / \mathrm{h}=\$ 5.5 / \mathrm{min}) \times(65.6-47.1 \mathrm{~min})$ & $\$ 101$ \\
\hline Anesthesia & $\$ 122 / \mathrm{h}$ & & \\
\hline Total provider fee & $\$ 329 / \mathrm{h}$ & & \\
\hline \multicolumn{4}{|l|}{ Implant cost } \\
\hline Long CMN & $\$ 2400$ & $\$(2400-1800)+\$ 230+\$ 130$ & $\$ 960$ \\
\hline Short CMN & $\$ 1800$ & & \\
\hline Additional locking screw & $\$ 230$ & & \\
\hline Reaming Rod & $\$ 130$ & & \\
\hline Total cost & - & $\$ 1147+\$ 101+\$ 960$ & $\$ 2208$ (per long CMN) \\
\hline Overall cost per reoperation & - & $\$ 2208 \times 83$ & $\$ 183,264$ \\
\hline Overall cost per refracture & - & $\$ 2208 \times 154$ & $\$ 340,032$ \\
\hline Average cost of reoperation & $\$ 30,000$ & - & - \\
\hline Difference in cost for reoperation & - & $\$ 183,264 / \$ 30,000$ & 6.1-fold \\
\hline Difference in cost for refracture & - & $\$ 340,032 / \$ 30,000$ & 11-fold \\
\hline
\end{tabular}


Taking a number needed to treat to harm for refracture of 154 , assuming the refracture requires reoperation, the total additional cost is $(\$ 2208 \times 154=) \$ 340,032$. Taking the lower NNTH for all-cause reoperation (83), by the same calculation we find an additional cost of $\$ 183,264$ for the long CMN. Therefore, whether considering reoperation in general or reoperation only after refracture, the additional cost of long CMN is considerable.

This must be weighed against the cost of revision of a periprosthetic fracture following use of a CMN. Revision of a periprosthetic fracture is costly and not without complication. However, the cost of revision surgery (refixation or arthroplasty) for failure of primary fixation in 2014 was found to be on average $\$ 30,000$ (revision hip arthroplasty ranging from $\$ 20,000$ to $\$ 40,000$ ) [24-29]. This number pales into comparison to the added overall cost of the long CMN, and this is based on a conservative estimate. In addition, the charge to the patient could easily be up to five- or six-fold this amount. Therefore, from a cost-benefit analysis standpoint, the cost of using long $\mathrm{CMN}$ over 154 cases represents roughly five- to ten-times the cost of using short nails over the same period and having one revision.

There are several other factors that favor short nails. First, short nails are technically easier as the inter-lock screws may be placed with the help of a jig. This allows lower-volume surgeons to safely and efficiently lock the nail distally. Second, short nails have demonstrably less blood loss and need for transfusion [13, 14]. These factors make short nails especially more attractive in the older patient with multiple medical comorbidities. The cumulative effect of these factors is not known. In addition, given the findings of the power analysis, which demonstrated that nearly 8500 patients would be needed to reach true statistical significance, it is likely that the statistically insignificant differences in refracture and reoperation rates are not clinically significant to many orthopaedic surgeons.

The primary limitation of this systematic review is the limited power. A large multi-center database study would be necessary to prove statistical significance for refracture and reoperation rates. Given the increased blood loss, operative time and fiscal cost associated with long compared to short CMN, regardless of whether refracture or reoperation rates are proven significantly higher by a better powered analysis, there is still a role for the short CMN as a faster, safer, less expensive, and less invasive option for patients with an trochanteric femur fracture without subtrochanteric extension.

\section{Compliance with ethical standards}

Funding None.
Research involving human participants/animals This article does not contain any studies with human participants or animals performed by any of the authors.

Conflict of interest The authors declare that they have no conflict of interest.

Informed consent For this type of study formal consent is not required.

Disclaimers Some authors are employees of the United States Federal Government and the US Army. The opinions or assertions contained herein are the private views of the authors and are not to be construed as official or reflecting the views of William Beaumont Army Medical Center, the Department of Defense, or US government. The American College of Surgeons National Surgical Quality Improvement Program and the hospitals participating in the ACS NSQIP are the source of the data used herein; they have not verified and are not responsible for the statistical validity of the data analysis or the conclusions derived by the authors.

Open Access This article is distributed under the terms of the Creative Commons Attribution 4.0 International License (http://crea tivecommons.org/licenses/by/4.0/), which permits unrestricted use, distribution, and reproduction in any medium, provided you give appropriate credit to the original author(s) and the source, provide a link to the Creative Commons license, and indicate if changes were made.

\section{References}

1. Cooper C, Campion G, Melton LJ (1992) Hip fractures in the elderly: a world-wide projection. Osteoporosis Int 2(6):285-289

2. Hallal PC, Andersen LB, Bull FC, Guthold R, Haskell W, Ekelund U (2012) Global physical activity levels: surveillance progress, pitfalls, and prospects. Lancet 380(9838):247-257

3. Kannus P, Parkkari J, Sievanen H, Heinonen A, Vuori I, Jarvinen M (1996) Epidemiology of hip fractures. Bone 18(1):57S-63S

4. Brauer CA, Coca-Perraillon M, Cutler DM, Rosen AB (2009) Incidence and mortality of hip fractures in the United States. JAMA 302(14):1573-1579

5. Hu F, Jiang C, Shen J, Tang P, Wang Y (2012) Preoperative predictors for mortality following hip fracture surgery: a review and meta-analysis. Injury 43(6):676-685

6. Barton TM, Gleeson R, Topliss C, Greenwood R, Harries WJ, Chesser TJ (2010) A comparison of the long gamma nail with the sliding hip screw for the treatment of AO/OTA 31-A2 fractures of the proximal part of the femur: a prospective randomized trial. J Bone Joint Surg Am 92(4):792-798

7. Lindskog DM, Baumgaertner MR (2004) Unstable intertrochanteric hip fractures in the elderly. J Am Acad Orthop Surg 12(3):179-190

8. Palm H, Jacobsen S, Sonne-Holm S, Gebuhr P, Hip Fracture Study Group (2007) Integrity of the lateral femoral wall in intertrochanteric hip fractures: an important predictor of a reoperation. J Bone Joint Surg Am 89(3):470-475

9. Mohan R, Karthikeyan R, Sonanis SV (2000) Dynamic hip screw: does side make a difference? Effects of clockwise torque on right and left DHS. Injury 31(9):697-699

10. Baumgaertner MR, Curtin SL, Lindskog DM, Keggi JM (1995) The value of the tip-apex distance in predicting failure of fixation of peritrochanteric fractures of the hip. J Bone Joint Surg Am 77(7):1058-1064 
11. Anglen JO, Weinstein JN, American Board of Orthopaedic Surgery Research Committee (2008) Nail or plate fixation of intertrochanteric hip fractures: changing pattern of practice. A review of the American Board of Orthopaedic Surgery Database. J Bone Joint Surg Am 90:700-707

12. Forte ML, Virnig BA, Eberly LE, Swiontkowski MF, Feldman R, Bhandari M, Kane RL (2010) Provider factors associated with intramedullary nail use for intertrochanteric hip fractures. J Bone Joint Surg Am 92(5):1105-1114

13. Boone C, Carlberg KN, Koueiter DM, Baker KC, Sadowski J, Wiater PJ, Nowinski GP, Grant KD (2014) Short versus long intramedullary nails for treatment of intertrochanteric femur fractures (OTA 31-A1 and A2). J Orthop Trauma 28(5):E96E100

14. Hou Z, Bowen TR, Irgit KS, Matzko ME, Andreychik CM, Horwitz DS, Smith WR (2013) Treatment of pertorchanteric fractures (OTA 31-A1 and A2): long versus short ephalomedullary nailing. J Orthop Trauma 27(6):318-324

15. Norris R, Bhattacharjee D, Parker M (2012) Occurrence of secondary fracture around intramedullary nails used for trochanteric hip fractures: a systematic review of 13,568 patients. Injury 43:706-711

16. Vaughn J, Cohen E, Vopat BG, Kane P, Abbood E, Born C (2014) Complications of short versus long cephalomedullary nail for intertrochanteric femur fractures, minimum 1 year follow-up. Eur J Orthop Surg Traumatol 25(4):665-670

17. Kleweno C, Morgan J, Redshaw J, Harris M, Rodriguez E, Zurakowski D, Vrahas M, Appleton P (2014) Short versus long cephalomedullary nails for the treatment of intertrochanteric hip fractures in patients older than 65 years. J Orthop Trauma 28(7):391-397

18. Welch V, Petticrew M, Tugwell P, Moher D, O'Neill J, Waters E, White H (2012) PRISMA-Equity 2012 extension: reporting guidelines for systematic reviews with a focus on health equity. PLoS Med 9(10):e1001333
19. Atkins D, Best D, Briss PA, Eccles M, Falck-Ytter Y, GRADE Working Group et al (2004) Grading quality of evidence and strength of recommendations. BMJ 328:1490

20. Macario A (2010) What does one minute of operating room time cost? J Clin Anesth 22:233-236

21. Abouleish AE, Dexter F, Whitten CW, Zavaleta JR, Prough DS (2004) Quantifying net staffing costs due to longer-than-average surgical case durations. Anesthesiology 100:403-412

22. Available at: http://www1.salary.com/orthopedic-surgeon-hourlywages.html. Accessed 1 March 2015

23. Available at: http://www.healthcareworkersalary.com/physicians/ orthopedic-surgeon-salary/?doing_wp_cron $=1425325586.55460$ 59608459472656250. Accessed 1 March 2015

24. Swart E, Makhni EC, Macaulay W, Rosenwasser MP, Bozic KJ (2014) Cost-effectiveness analysis of fixation options for intertrochanteric hip fractures. J Bone Joint Surg Am 96:1612-1620

25. Thakar C, Alsousou J, Hamilton TW, Willett K (2010) The cost and consequences of proximal femoral fractures which require further surgery following initial fixation. J Bone Joint Surg $\mathrm{Br}$ 92(12):1669-1677

26. Palmer SJ, Parker MJ, Hollingworth W (2000) The cost and implications of reoperation after surgery for fracture of the hip. J Bone Joint Surg Br 82(6):864-886

27. Bozic KJ, Katz P, Cisternas M, Ono L, Ries MD, Showstack J (2005) Hospital resource utilization for primary and revision total hip arthroplasty. J Bone Joint Surg Am 87(3):570-576

28. Bozic KJ, Morshed S, Silverstein MD, Rubash HE, Kahn JG (2006) Use of costeffectiveness analysis to evaluate new technologies in orthopaedics. The case of alternative bearing surfaces in total hip arthroplasty. J Bone Joint Surg Am 88(4):706-714

29. Crowe JF, Sculco TP, Kahn B (2003) Revision total hip arthroplasty: hospital cost and reimbursement analysis. Clin Orthop Relat Res 413:175-182 